\title{
José Eduardo Rueda Enciso. El trópico desmitificado. HOMBRE Y NATURALEZA BAJO EL ILUMINISMO. BUCARAMANGA: UNIVERSIDAD INDUSTRIAL DE SANTANDER, 2015, 354 PP.
}

DOI: http: / / dx.doi.org/10.29078/rp.v0i47.683

Luego de un arduo forcejeo con fuentes e hipótesis, el autor pone al lector en diálogo con los destellos más sobresalientes, a su juicio, del legado de las andanzas iluministas en la Nueva Granada. Digo andanzas porque los actores de esta pesquisa se movieron de un lado a otro, tragándose montañas y enfrentando los enigmas de unas ciencias, como las naturales, en construcción. Harto se ha escrito sobre los bemoles de las expediciones botánicas. No obstante en este trabajo José Eduardo Rueda enriquece la historiografía de un período clave para el estudio del proceso que dio origen a la independencia de la metrópoli española, aportando nuevos elementos que permiten comprender el papel de los ilustrados en la agencia política y científica a finales del siglo XVIII e inicios del XIX.

El título del libro, a mi modo de ver, debió llamarse el Redescubrimiento de América, hipotesis que Rueda demuestra tras un minucioso trabajo de fuentes que lo llevan a recrear el pensamiento y acción de expedicionarios e intelectuales que lograron recrear la ilustración española en el Nuevo Mundo. Dicho redescubrimiento pasó por la observación y caracterización de la naturaleza y la interacción entre esta y los restos de los pueblos originarios diezmados cultural y físicamente por los conquistadores. Su tesis central radica en la forma cómo dichas investigaciones, en el contexto del conocimiento útil, sirvieron de punta de lanza para los posteriores procesos económicos de los que se valió el imperio para el desarrollo comercial de la metrópoli.

La obra está estructurada en seis capítulos. Cada uno de estos dedicado en particular a quienes encarnaron las ideas ilustradas en el trópico. Desde Ulloa hasta Tadeo Lozano, pasando por el más emblemático de todos: José Celestino Mutis. El texto, jugoso en citas y pies de páginas, no deja nada al azar. Por el contrario, todo parece haber sido el resultado de largas jornadas de cavilación entre archivo y escritura. Rueda hace las veces del redescubridor de los actores centrales de esta historia que, como lo logra argumentar, tuvieron la no fácil tarea de desmitificar el trópico desde un enfoque eclético que logró convivir bajo el dualismo ciencia-religión. Sin duda, se trata de un aporte al debate historiográfico sobre antecedentes, contexto y consecuencias de la razón ilustrada en torno a problemas como el nacimiento de las ciencias en América, la historicidad del utilitarismo y el papel de la antropología cultural. 
El primer capítulo está dedicado a la figura de Antonio de Ulloa, un clérigo que pisó tierra ecuatoriana el 24 de mayo de 1736 con una misión concreta: revisar y corregir la geodesia del territorio. Sin embargo, el merito de Ulloa y sus colegas (los franceses Bourguer y La Condamine, y Jorge Juan) sobrepasó esta meta. Incursionó en otros detalles desconocidos como la historia natural y lingüística, y las explotaciones agrícolas, ganaderas y mineras "con el fin de potenciarlos" (26). Para el autor del libro, este expedicionario fue un pionero de la historia como "una nueva forma de entender a América" (27), a la vez uno de los precursores de estudios sobre botánica, zoología, magnetismo, y mineralogía. Su método al que hoy podríamos ubicar en el campo del constructivismo, fue innovador porque concebía "el conocimiento como una larga serie de peldaños apoyados unos de otros" (34). Puso, como sus sucesores, la comprensión de la naturaleza americana al servicio de la expansión económica de la Corona española. Para la antropología ecológica contemporánea, las cavilaciones de Ulloa son valiosas aunque desconocidas. El merito de Rueda es sacarlas a flote, sobre todo cuando sostiene que "Ulloa advirtió cómo, a medida que el hombre tenía una relación más estrecha con la naturaleza, mucho más cercana, su cultura era simple, mientras que cuando el hombre se alejaba de la naturaleza, esto es, a medida que la transformaba y entendía para su bien, el grado de su cultura era más complejo" (47).

José Celestino Mutis, considerado en el texto como el oráculo del Virreinato del Nuevo Reino de Granada, ocupa el capítulo dos de este Trópico desmitificado. A diferencia de otras contribuciones sobre el más emblemático de los expedicionarios, José Eduardo Rueda nos presenta a un Mutis racional, calculador, empresario y contrario a los intereses de las clases subalternas, aunque por la "mezcla de doctrinas creó una actitud crítica e independiente, sin prejuicios, lo que le llevó a ser innovador, sin comprometerse radicalmente en el cambio" (60). Para Rueda, el médico y botánico se hizo rico explotando la quina. Sin que fuera lo más importante, el autor ata a Mutis con otros aspectos icónicos de su radio de influencia en el marco de las ciencias útiles: las tensiones entre la filosofía natural de corte copernicano y la enseñanza tradicional, el surgimiento de los primeros círculos masónicos, su relación con los jesuitas, y la creación de una especie de red de sabedores entre los indígenas. La tesis más fuerte del autor alrededor de Mutis es su desacuerdo con quienes lo han considerado el padre de la ecología en América "cuando en realidad lo que hizo [...] fue tener un interés económico: trató de preservar una especie -la quina- mediante la racionalización de su producción y acopio" (96). A través de Mutis, los investigadores del extractivismo colonial y neocolonial podrán encontrar algunas elementos del racionalismo ilustrado que puso sello utilitario al destino de las ciencias naturales en Colombia y el resto de América Latina a través de todo el siglo XX, hasta hoy. 
El capítulo III es una prolongación del apartado dedicado a los rasgos generales de José Celestino. Está centrado en el análisis del papel geopolítico de las expediciones botánicas en el dominio europeo del territorio desde el siglo XVI. Rueda, apoyado en la interpretación de datos, apunta aquí a desarrollar su hipotesis del Redescubrimiento de América, y en particular a la idea de cómo la ciencia se constituyó en uno de los pilares que permitieron sustentar el capitalismo naciente. Aprovecha las entretelas de la Real Expedición Botánica liderada por Mutis para develar algunos aspectos ocultos, como su papel contrainsurgente en la revuelta comunera de 1781 a través de las "labores informativas" (147) que en realidad lo fueron pero de espionaje, como si se tratara de un "verdadero servicio de inteligencia" (149). Uno de sus protagonistas, fray Diego de García, pone condimento a una narrativa interesada en desmontar la imagen altruista de la Expedición y, por tanto, los intereses calculadores del Virreinato. A la postre Rueda, en su faena desmitificadora, concluye que quien en realidad maximizó las labores de "inteligencia” fue Mutis, porque arrumó y utilizó la información para sus fines comerciales a través de la explotación de los bosques de quina. Particularmente, y dadas las contradicciones tácitas expuestas por el autor, se pudo haber quedado corto en una idea que queda flotando en el texto al plantear que la Expedición Botánica de Mutis sentó las “bases de una naciente identidad nacional" (147).

Los últimos tres capítulos dejan ver los efectos contradictorios de la Ilustración americana, a través de un trío de actores sobresalientes: Manuel del Socorro Rodríguez, el sabio Caldas y Jorge Tadeo Lozano. Del primero se ha dicho que fue el impulsor del periodismo escrito en Santafé de Bogotá y su condición de ser uno de los generadores de un "clima pre revolucionario" (177), pero no de sus aportes a la antropología y al redescubrimiento de América a través de la historia (187), y menos de su posición radical ante la conquista y colonización porque "arrasó con la cultura material de los primitivos habitantes de América" (188), de ahí que Rodríguez propuso la utilización de la antropología, la historia, la lingüística y la antropología para "salvar" los fragmentos materiales del "edificio" cultural demolido por los europeos (189). A su turno, Francisco José de Caldas que nos transmite Rueda, es un sabio atrapado en las contradicciones etnocéntricas del criollato neogranadino. Sin desconocer su postura frente a los daños causados al indígena por la conquista y colonización española, el autor acierta al poner en consideración las dicotomías planteadas por Caldas entre bárbaro / civilizado como mecanismo para analizar las relaciones complejas entre sociedad y cultura. Se apartó de las redes de Mutis y "tuvo reservas frente al saber popular" (233), mientras que las "diferencias racionales eran, en opinión de Caldas, una necesidad" (235), lo llevó a considerar que el negro debía ser 
un elemento dedicado a servir como mano de obra y como un ser pensante (254). Tadeo Lozano, quizás el más liberal del tridente, fusilado al igual que Caldas, desde la Sociedad Patriótica que impulsó vio en la educación, la agricultura, la industria, el comercio y la política, los campos del progreso. El autor deja en claro que junto a Rodríguez fueron los principales representantes de la corriente antropológica de la época. Fue más allá que todos: América hispánica como territorio mestizo, empezando por la blanca o árabe española (265).

En sus conclusiones, la obra redondea las hipótesis expuestas y demostradas alrededor de las relaciones sociedad-naturalezas tejidas por la ilustración española y el los desarrollos del pensamiento americanista. El libro, como he insistido en esta reseña, es un valioso aporte a la comprensión del pensamiento borbónico, el cual influyó en los procesos de modernización a partir del desarrollo de las ciencias naturales en función de la apropiación utilitarista de los recursos naturales, asuntos cada vez más candentes en el debate contemporáneo sobre los factores históricos que han incidido en la configuración de la crisis socioambiental y el papel de la academia latinoamericana en su estudio y comprensión.

Carlos Alfonso Victoria Mena Universidad Tecnológica de Pereira, Colombia 